\title{
Gastric Anastomotic Leakage
}

National Cancer Institute

\section{Source}

National Cancer Institute. Gastric Anastomotic Leakage. NCI Thesaurus. Code C78310.

Leakage due to breakdown of a gastric anastomosis. 